\title{
HANDBOOK ON NUCLEAR LAW: IMPLEMENTING LEGISLATION ${ }^{1 *}$

\author{
Stolber, Carloton; Cherf, Abdelmadild; Tonhauser, Wolfram; Vez C., \\ María de Lourdes, IAEA, VIENA, 2010. 153 pP.
}

IGNACIO URBINA MOLFINO2*

No es novedad que durante los últimos años nuestro país ha tenido dificultades para satisfacer la creciente demanda energética. En la medida que nuestra nación progresa, se hace cada vez más difícil resolver los problemas energéticos. Por lo anterior, nuestra política energética ha comenzado a evaluar diversas alternativas para poder satisfacer a largo plazo, y de manera consistente, los diversos requerimientos energéticos de la población. Una alternativa que ha comenzado a discutirse recientemente es la implementación de la energía nuclear.

Como es sabido, el desarrollo de la energía nuclear en cualquier país requiere no sólo de varios años de estudio y preparación de capital humano avanzado, altamente calificado para operar plantas nucleares, sino que además, implica usualmente severos cambios a los sistemas jurídicos vigentes en materia energética. A lo anterior, también, cabe agregar las legítimas demandas de la población respecto a proyectos de tal naturaleza, que deben satisfacer a lo menos dos requerimientos: en primer lugar, todo proyecto de energía nuclear debe cumplir con los más altos estándares de seguridad, y en segundo lugar, todo proyecto debe propender al mayor cuidado posible del medioambiente. Una legislación nuclear bien diseñada puede contribuir seriamente al desarrollo sustentable de Chile, mientras que una legislación deficiente puede poner seriamente en riesgo tanto la salud de la población, como la seguridad y el medioambiente.

El libro que comentamos es un manual que ha sido preparado como una guía para que los países en vías de desarrollo adopten sus legislaciones nucleares. Ha sido elaborado por la misma IAEA (Organismo Internacional de Energía Atómica, dependiente de las Naciones Unidas, con sede en Viena). No obstante ser presentado como edición única, sigue, aunque con cambios sustanciales, a un anterior manual que fuera publicado por la misma agencia el año 2003.

\footnotetext{
$1^{*}$ Colaboración recibida el 7 de marzo y aprobada el 19 de abril de 2011.

2** Abogado de la Superintendencia del Medio Ambiente; Licenciado en Derecho, Pontificia Universidad Católica de Chile; Profesor Instructor de la misma Facultad. Correo electrónico: iurbina@conama.cl.
} 
Tiene por finalidad general presentar pautas legislativas para el desarrollo de marcos jurídicos que aseguren los usos pacíficos de la energía nuclear y de la radiación ionizante. Es así como la estructura del libro es bastante similar al índice de cualquier ley vigente.

El texto está dividido en quince capítulos. El primero, destinado a los aspectos más básicos de toda ley de energía nuclear, como el título, el preámbulo, las definiciones, los objetivos que debe seguir la ley y cuál debe ser su alcance. El segundo capítulo plantea todas las características que ha de tener el ente regulador. En el tercero, uno de los más importantes, se establecen las condiciones de autorizaciones o licencias, así como los estándares de inspección, fiscalización y sanción. El cuarto y quinto capítulo están destinados al examen de la protección de la radiación y de las fuentes radiactivas, respectivamente. El sexto capítulo abarca probablemente una de las materias más complejas, que por su complejidad técnica no es de fácil determinación legal, como es la seguridad en las instalaciones nucleares y en las operaciones de desmantelamiento. Los capítulos siete a diez tratan materias tan importantes como las situaciones de emergencia, la extracción y procesamiento de material nuclear, el transporte del material radiactivo y sobre el tratamiento de los desechos radiactivos. El undécimo capítulo está orientado a explicar el interesante problema de la responsabilidad por daño nuclear. Los capítulos trece y catorce explican cómo debe ser la legislación en cuanto a la exportación e importación de material nuclear, así como de la protección contra potenciales amenazas y tráfico ilícito. Finalmente, el capítulo quince versa sobre la entrada en vigencia de la ley nuclear y de cómo ha de hacerse una transición exitosa a un nuevo sistema legal.

El manual presenta en cada capítulo ejemplos y sugerencias de cómo han de ser los artículos de la ley que versen sobre los temas tratados. Asimismo, incluye una extensa bibliografía, segmentada por capítulos, constituyendo así una excelente fuente para todo aquel que desee introducirse en el derecho nuclear.

Quizás, aunque sea un detalle, se echa de menos un aspecto que se encontraba presente (y excelentemente bien presentado) en el manual preparado por la IAEA el año 2003 y que fue omitido en el nuevo manual que comentamos, a saber, una explicación detallada de los principios que subyacen a la legislación nuclear. Sin duda, contribuyen a la comprensión global de los problemas de toda ley nuclear comprender las exigencias que imponen los principios de seguridad técnica, de seguridad radiológica, de responsabilidad, de autorización, de control continuo, de compensación, de desarrollo sustentable, de cumplimiento, de independencia, de transparencia, de cooperación internacional, entre otros. Es precisamente la comprensión adecuada de los mencionados principios lo que permite a los legisladores y entidades regulatorias resolver adecuadamente los diversos y complejos problemas que se susciten en el tiempo. 
No obstante, el libro nos parece un aporte importantísimo en materias de derecho nuclear. Chile está avanzando hacia temas energéticos que pudieran derivar en la implementación de la energía nuclear y el libro que comentamos es la fuente precisa e indicada para, en primer lugar, evaluar nuestra propia legislación nuclear vigente y, en segundo lugar, pavimentar el camino que debemos seguir para permitir un desarrollo adecuado en estas materias. 
